18 Wald N, Kiryluk S, Darby S, Doll R, Pike M, Peto R. UK smoking statistics. Oxford: Oxford University Press, 1988.

19 Doll R, Peto R. The causes of cancer: quantitative estimates of avoidable risks of cancer in the United States today. J Natl Cancer Inst 1981;66:1191308

20 Thun MJ, Day-Lalley CA, Calle EE, Flanders WD, Heath CA. Excess mortality among cigarette smokers: changes in a 20-year interval. Am J Pub Health 1995:85:1293-30.

21 Peto R. Overview of cancer time-trend studies in relation to changes in cigarette manufacture. In: Zaridze D, Peto R, eds. Tobacco: a major international health hazard. Lyons: International Agency for Research on Cancer, 1986:211-26. (IARC scientific publication No 74.)
22 Doll R, Gray R, Hafner B, Peto R. Mortality in relation to smoking: 22 years' observation on female British doctors. BMJ 1980;280:967-71

23 Doll R, Darby S, Whitley E. Trends in mortality from smoking-related diseases. In: Charlton J, Murphy M, eds. The health of adult Britain, 1841-1994. Vol 1. London: Stationery Office, 1997:128-55.

24 Peto R, Chen ZM, Boreham J. Tobacco-the growing epidemic. Nature Med 1999;5:15-7.

25 Peto R, Lopez AD. The future worldwide health effects of current smoking patterns. In: Koop CE, Pearson CE, eds. Global health in the 21st century. New York: Jossey-Bass, 2000.

(Accepted 7July 2000)

\title{
Smoking reduction with oral nicotine inhalers: double blind, randomised clinical trial of efficacy and safety
}

Chris T Bolliger, Jean-Pierre Zellweger, Tobias Danielsson, Xandra van Biljon, Annik Robidou, Åke Westin, André P Perruchoud, Urbain Säwe

\begin{abstract}
Objectives To determine whether use of an oral nicotine inhaler can result in long term reduction in smoking and whether concomitant use of nicotine replacement and smoking is safe.

Design Double blind, randomised, placebo controlled trial. Four month trial with a two year follow up. Setting Two university hospital pulmonary clinics in Switzerland.

Participants 400 healthy volunteers, recruited through newspaper advertisements, willing to reduce their smoking but unable or unwilling to stop smoking immediately.

Intervention Active or placebo inhaler as needed for up to 18 months, with participants encouraged to limit their smoking as much as possible.

Main outcome measures Number of cigarettes smoked per day from week six to end point. Decrease verified by a measurement of exhaled carbon monoxide at each time point compared with measurement at baseline.

Results At four months sustained reduction of smoking was achieved in $52(26 \%)$ participants in the active group and $18(9 \%)$ in the placebo group $(\mathrm{P}<0.001$; Fisher's test). Corresponding figures after two years were $19(9.5 \%)$ and $6(3.0 \%)(\mathrm{P}=0.012)$.

Conclusion Nicotine inhalers effectively and safely achieved sustained reduction in smoking over 24 months. Reduction with or without nicotine substitution may be a feasible first step towards smoking cessation in people not able or not willing to stop abruptly.
\end{abstract}

\section{Introduction}

The best way to prevent the detrimental health consequences of cigarette smoking is to quit, and efforts to date have focused on this strategy. ${ }^{2}$ Many smokers, however, find it impossible to quit, even with help, because of their dependence on nicotine, which is a highly addictive psychoactive drug. ${ }^{3}$ Nicotine replacement therapy is an established pharmacological aid to help smokers quit and has consistently been shown almost to double the abstinence rate, irrespective of the level of additional interventions. ${ }^{4}$ Increasing experience with trials on smoking cessation, however, has shown that successful abstinence is usually obtained in smokers with low to moderate nicotine dependence, whereas heavily dependent smokers have the highest relapse rates. ${ }^{5}$ Unfortunately this latter group has the highest cigarette consumption and is therefore at the highest risk of developing disease related to tobacco consumption.

Given that few smokers are ready to quit at any time, plus the fact that many smokers try to quit several times before succeeding, new treatment approaches are clearly needed. One such strategy could be to reduce tobacco consumption substantially in smokers who are unwilling or unable to quit right away. For such smokers, sustained reduction might reduce the known health risks by reducing tobacco exposure and may also move them towards the ultimate goal of quitting. ${ }^{6}$ In a preliminary study Fagerström et al showed that short term smoking reduction with nicotine replacement therapy over a period of five weeks was possible and that the combination of reduced smoking with nicotine replacement therapy was well tolerated. The efficacy and safety of nicotine replacement therapy in achieving sustained smoking reduction, however, has not yet been assessed. Another important issue is whether smoking reduction can increase motivation to quit in recalcitrant smokers.

Smoking cessation is no longer regarded as a dichotomous process (cessation or not) but rather as a continuum that entails several stages, as described by DiClemente and Prochaska. $^{9}$ There is empirical evidence to suggest that reduced smoking, also referred to as controlled smoking or harm reduction, is a therapeutic option for those smokers unable or unwilling to quit. Glasgow et $\mathrm{al}^{10}$ and Hughes et $\mathrm{al}^{11}$ found that smokers randomised to such an intervention were no less likely, and possibly even more likely, to quit smoking in the long term compared with smokers randomised to more conventional interventions. While not the first treatment of choice, reduced smoking might be considered for recalcitrant smokers unwilling to repeat traditional cessation attempts.
Respiratory

Division,

Department of

Internal Medicine,

University Hospital

4031 Basle,

Switzerland

Chris T Bolliger associate professor

Xandra van Biljon

registered nurse

André P

Perruchoud

professor

University Medical

Policlinic, CHUV,

1000 Lausanne,

Switzerland

Jean-Pierre

Zellweger

lecturer

Annik Robidou

registered nurse

Pharmacia and

Upjohn, 25109

Helsingborg,

Sweden

Tobias Danielsson

clinical research

manager

Åke Westin

head of biostatistics

Urbain Säwe

medical adviser

Correspondence to: C T Bolliger

ctb@gerga.sun.ac.za

BMJ 2000;321:329-33

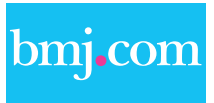

This article is part of the BMJ's randomised controlled trial of open peer review. Documentation relating to the editorial decision making process is available on the BMJ's website 
The oral nicotine inhaler, which is one of the newer nicotine replacement products, has been shown to be an effective aid for smoking cessation. ${ }^{12}{ }^{13}$ Use of a nicotine inhaler by smokers unwilling or unable to stop smoking completely might be a good approach to reducing cigarette consumption as the inhaler imitates some aspects of cigarette smoking and contains nicotine. We tested the efficacy and safety of the nicotine inhaler in achieving sustained smoking reduction.

\section{Methods}

Study design

Smokers were recruited into this two centre, double blind, placebo controlled, randomised clinical trial through newspaper advertisements that asked for healthy smokers who were unwilling or unable to quit but were interested in reducing their smoking. All participants were given information about possible ways to achieve this goal. Smoking cessation was recommended as the ultimate goal throughout the study.

\section{Participants}

Participants in the trial had to be at least 18 years of age, smoke 15 or more cigarettes a day, have a carbon monoxide concentration in exhaled air $\geqslant 10 \mathrm{ppm}$, have smoked regularly for three or more years, have failed at least one serious attempt to quit within the past 12 months, want to reduce smoking as much as possible with the help of the nicotine inhaler, be prepared to adhere to the protocol, and be willing to provide informed consent. Exclusion criteria were current use of nicotine replacement therapy or any other behavioural or pharmacological smoking cessation or reduction programme, use of other nicotinecontaining products, or any condition that might interfere with the study.

The ethics committees of the universities of Basle and Lausanne approved the study.

\section{Treatment}

Independent pharmacists dispensed either active or placebo inhalers according to a computer generated randomisation list. All smokers received information about the general implications of smoking and its effects on health. Participants were asked to reduce the number of cigarettes smoked daily as much as possible, and an initial reduction of 50\% was suggested.

The active treatment comprised nicotine replacement through an inhalation device (Nicorette Inhaler, Pharmacia and Upjohn). ${ }^{12}{ }^{13}$ The inhaler consists of a plastic mouthpiece into which a disposable cartridge containing $10 \mathrm{mg}$ nicotine and $1 \mathrm{mg}$ menthol is inserted. At room temperature the total available nicotine content is 4-5 mg per cartridge. The inhaler delivers about $13 \mu \mathrm{g}$ of nicotine per puff (average puff volume of $50 \mathrm{ml}$ ), which means that about 80 puffs are required to obtain $1 \mathrm{mg}$ nicotine. The placebo inhalers were identical in appearance and contained only menthol. Both treatment groups were allowed to use the inhalers as needed, with the recommendation to use between six and 12 cartridges over 24 hours. Participants were encouraged to decrease use of the inhaler after four months but were permitted to continue treatment for 18 of the 24 months in the study.

\section{Assessment}

After the initial telephone screening and baseline assessment participants were reassessed at the clinic after one, two, three, and six weeks and three, four, six, 12, 18, and 24 months. Counselling on smoking reduction was provided at each visit.

Admission criteria and demography, including the Fagerström test for nicotine dependence, ${ }^{14}$ reasons for reducing smoking, and medical and smoking history were assessed at baseline. At all key visits (baseline and months four, 12, and 24) we measured expired carbon monoxide concentrations, symptoms of withdrawal, smoking status, respiratory function, blood pressure, pulse, weight, plasma cotinine concentration, haematological variables, and concentrations of blood lipids and fibrinogen. We also assessed smoking status, intention to quit, compliance, concomitant medications, adverse events, and quality of life (with the SF-36 questionnaire). ${ }^{15}$ Reported adverse events and plasma cotinine concentrations served as a basis for the safety analysis of concomitant smoking and nicotine replacement therapy.

\section{Measures of outcome}

The primary efficacy measure (success) was defined as self reported reduction of daily cigarette smoking by at least $50 \%$ compared with baseline from week six to month four, the duration for which the study was powered. This reduction was verified by decreased carbon monoxide concentrations at week six and months three and four. Results up to 24 months are presented in this paper. Smoking cessation was defined as not smoking from week six and a carbon monoxide concentration $<10 \mathrm{ppm}$ at all subsequent visits. Smoking reduction and cessation are also presented with verification of carbon monoxide concentrations at each time point (point prevalence).

\section{Statistical analysis}

To ensure an adequate number of participants we recruited 200 smokers into each group, giving a total of 400 participants. The primary analysis was an intention to treat analysis including all participants who were randomised and received medication. As in other studies of smoking cessation studies participants who dropped out were regarded as treatment failures. All statistical methods were two tailed, and $\mathrm{P}$ values of $\leqslant 0.05$ were considered significant. Odds ratios together with corresponding confidence intervals were calculated when applicable, and Fisher's test was used for categorical and binary variables. Confidence intervals of means were calculated for continuous variables when applicable, and differences within participants were tested for with Wilcoxon's signed rank sum test.

\section{Results}

\section{Baseline characteristics and rates of follow up}

Table 1 shows the baseline characteristics of all enrolled participants. The only significant difference was that there were more women in the active 


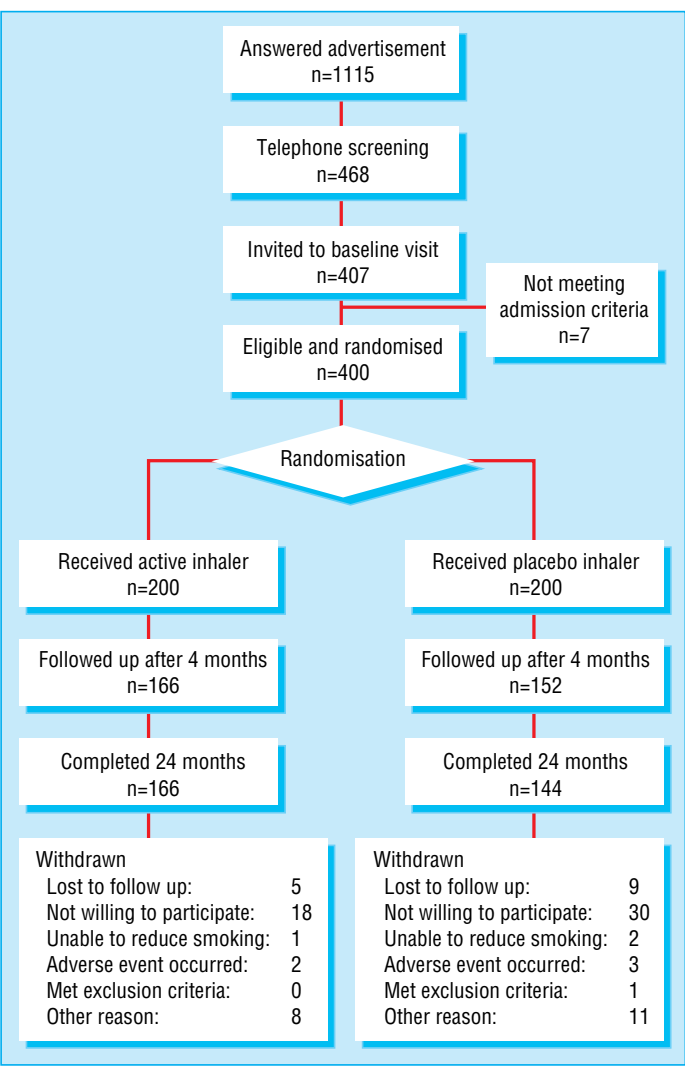

Progress of participants in trial of oral nicotine therapy as aid for reduction in cigarette smoking

treatment group. At each follow up visit there were more participants in the active treatment group than in the placebo group (figure).

\section{Treatment compliance}

Inhaler use decreased over time, as expected. Of participants present at week six, 222/368 (60\%) used the inhaler every day. Corresponding figures after four, 12 , and 18 months were 146/318 (46\%), 39/331 (12\%), and $30 / 289(10 \%)$, respectively. Participants in the active treatment group used an average of 4.5 cartridges a day after two weeks and 2.6 a day after 18 months; they reduced their cigarette intake significantly more than participants in the placebo group from week two onward. Table 2 shows inhaler use and reduction in the number of cigarettes smoked and exhaled carbon monoxide concentration in daily users for both the active and the placebo groups.
Table 1 Baseline demographic characteristics, including smoking status and history. Values are expressed as means (SD); range

\begin{tabular}{lcc} 
& Placebo $(\mathbf{n}=\mathbf{2 0 0})$ & Active $(\mathbf{n}=\mathbf{2 0 0})$ \\
\hline No of men & 104 & 86 \\
\hline Age (years) & $45.8(10.5) ; 22-77$ & $46.4(10.5) ; 23-79$ \\
\hline Weight $(\mathrm{kg}):$ & & \\
\hline Women & $62.9(10.6) ; 48-109$ & $64.0(11.2) ; 43-120$ \\
\hline Men & $81.5(12.3) ; 57-121$ & $80.1(12.6) ; 58-130$ \\
\hline Age when started smoking (years) & $17.1(2.7) ; 11-35$ & $18.2(4.4) ; 12-45$ \\
\hline No of cigarettes smoked/day & $30.3(12.1) ; 15-70$ & $28.2(11.4) ; 15-70$ \\
\hline Exhaled CO concentration $(\mathrm{ppm})$ & $27.1(11.1) ; 10-61$ & $27.1(11.5) ; 10-61$ \\
\hline FTND score & $5.6(2.0) ; 1-10$ & $5.5(2.1) ; 1$-10 \\
\hline
\end{tabular}

$\mathrm{CO}=$ carbon monoxide; FTND=Fagerström test for nicotine dependence.

\section{Efficacy}

Table 3 shows that the success rates from week six onwards were significantly higher for the active group at four, 12, and 24 months. The point prevalence reduction rates were also higher in the active treatment group, but the difference was significant only at four months $(\mathrm{P}<0.001)$, with only a trend towards significance at 12 months $(\mathrm{P}=0.085)$ and 24 months $(\mathrm{P}=0.357)$.

The sustained rates of complete abstinence were low in both groups, with no significant differences between groups. Four participants in the active treatment group and one in the placebo group were not smoking any cigarettes at four, 12, and 24 months. The point prevalence cessation rates, however, increased over time, and 38 participants were not smoking after 24 months (table 3).

\section{Safety}

Adverse events were reported by 114 participants in the placebo group (193 adverse events) and 113 participants in the active treatment group (227 adverse events). Fifty three serious events occurred, none of which was related to treatment. Two local symptoms were significantly more common in the active treatment group than the placebo group: throat irritation (14 $v 4 ; 95 \%$ confidence interval for odds ratio 1.13 to 15.6$)$ and coughing (13 $v 4 ; 1.1$ to 10.6$)$. The total numbers of adverse events relating to symptoms usually associated with nicotine (nausea, vomiting, and palpitation) were evenly distributed between the groups; nausea or nausea and vomiting was reported by eight in the placebo group and nine in the active treatment group, with corresponding figures for palpitation of two and one, respectively.

Table 2 Number of inhalers used, reduction in number of cigarettes smoked, and exhaled carbon monoxide concentration in participants using inhaler every day; active and placebo treatment groups. Values are expressed as means (SD); range

\begin{tabular}{|c|c|c|c|c|c|c|c|c|}
\hline \multirow[b]{2}{*}{ Time point } & \multicolumn{4}{|c|}{ Intervention group } & \multicolumn{4}{|c|}{ Placebo group } \\
\hline & $\begin{array}{c}\text { No of } \\
\text { participants }\end{array}$ & $\begin{array}{l}\text { No of } \\
\text { inhalers/day }\end{array}$ & $\begin{array}{c}\text { Cigarettes/day as \% of } \\
\text { baseline }\end{array}$ & $\begin{array}{c}\mathrm{CO} \text { as } \% \text { of baseline } \\
\text { value }\end{array}$ & $\begin{array}{c}\text { No of } \\
\text { participants }\end{array}$ & $\begin{array}{c}\text { No of } \\
\text { inhalers/day }\end{array}$ & $\begin{array}{c}\text { Cigarettes/day as \% of } \\
\text { baseline }\end{array}$ & $\begin{array}{c}\mathrm{CO} \text { as } \% \text { of baseline } \\
\text { value }\end{array}$ \\
\hline 1 week & 169 & $4.3(2.1) ; 1-12$ & 53.0 (19.9); 4.3-105 & 79.8 (34.3); 12.5-208 & 162 & $4.4(2.0) ; 1-12$ & 56.4 (18.3); 9.5-100 & 83.4 (30.6); 29.0-171 \\
\hline 2 weeks & 168 & $4.5(2.0) ; 1-10$ & $48.5(20.0) ; 0.0-100^{*}$ & 73.6 (31.4); 11.1-182 & 164 & $4.9(2.0) ; 1-12$ & 54.7 (18.9); 0.0-104* & $82.0(37.9) ; 13.6-255$ \\
\hline 6 weeks & 117 & $4.3(2.1) ; 1-12$ & 45.1 (23.8); 0.0-100† & 68.4 (31.4); 11.1-155‡ & 104 & $4.7(2.0) ; 1-14$ & 55.8 (18.2); 1.9-100† & 84.1 (50.0); 16.1-450‡ \\
\hline 4 months & 84 & $3.9(2.0) ; 1-10$ & 42.7 (24.3); 0.0-100§ & 58.3 (32.1); 5.6-141§ & 62 & 4.0 (1.9); $1-10$ & 52.0 (21.7); 0.0-100§ & $71.1(26.5) ; 12.5-170 \S$ \\
\hline 12 months & 27 & $3.5(1.9) ; 1-7$ & 32.6 (27.3); 0.0-839 & 63.7 (42.4); 14.3-180 & 12 & $2.8(2.1) ; 0-6$ & 56.3 (33.4); 0.0-133ף & 83.9 (61.4); 9.8-250 \\
\hline 18 months & 22 & 2.6 (1.7); $0-6$ & 36.2 (29.6); $0.0-100^{* *}$ & 71.0 (58.8); 7.9-222 & 8 & $3.9(2.5) ; 1-8$ & $67.2(27.8) ; 20.0-100^{\star * *}$ & 81.7 (41.4); 50.0-177 \\
\hline
\end{tabular}

$P$ values (Wilcoxon's rank sum test) for difference between intervention and placebo: ${ }^{*} P=0.004 ; \dagger P<0.001 ; \ddagger P=0.003 ; \xi P=0.01 ; \uparrow P=0.03 ; * * P=0.02$. 
Table 3 Efficacy results measured as sustained and point prevalence reductions in smoking and point prevalence abstinence rates according to treatment with oral nicotine inhaler (active treatment) or placebo

\begin{tabular}{|c|c|c|c|c|c|}
\hline Definition & Time point (months) & $\begin{array}{c}\text { No }(\%) \text { with active } \\
\text { treatment }\end{array}$ & No (\%) with placebo & Odds ratio $(95 \% \mathrm{Cl})$ & $P$ value (Fisher's test) \\
\hline \multicolumn{6}{|l|}{ Sustained } \\
\hline \multirow[t]{3}{*}{ Reduction* } & 4 & $52(26.0)$ & $18(9.0)$ & 3.55 (2.04 to 6.19$)$ & $<0.001$ \\
\hline & 12 & $26(13.0)$ & $8(4.0)$ & 3.59 (1.65 to 7.80$)$ & 0.002 \\
\hline & 24 & $19(9.5)$ & $6(3.0)$ & 3.39 (1.39 to 8.29$)$ & 0.012 \\
\hline \multicolumn{6}{|c|}{ Point prevalence } \\
\hline \multirow[t]{3}{*}{ Reduction† } & 4 & $83(41.5)$ & $44(22.0)$ & 2.52 (1.63 to 3.87$)$ & $<0.001$ \\
\hline & 12 & $59(29.5)$ & $43(21.5)$ & 1.53 (0.97 to 2.40$)$ & 0.085 \\
\hline & 24 & 55 (27.5) & $46(23.0)$ & $1.27(0.81$ to 2.00$)$ & 0.357 \\
\hline \multirow[t]{3}{*}{ Abstinence } & 4 & $13(6.5)$ & $4(2.0)$ & 3.41 (1.16 to 10.01$)$ & 0.044 \\
\hline & 12 & $16(8.0)$ & $12(6.0)$ & $1.36(0.63$ to 2.95$)$ & 0.557 \\
\hline & 24 & $21(10.5)$ & $17(8.5)$ & 1.26 (0.65 to 2.47$)$ & 0.609 \\
\hline
\end{tabular}

* Sustained reduction in number of cigarettes smoked daily by at least $50 \%$ from week 6 , verified by decreased carbon monoxide concentrations compared with baseline.

†Point prevalence reduction of cigarettes smoked daily by at least $50 \%$ at months 4,12 , and 24 , verified by decreased carbon monoxide concentrations compared with baseline.

¥No cigarettes smoked, verified by carbon monoxide concentrations $<10 \mathrm{ppm}$ at months 4,12 , and 24 .

\section{Intention to quit}

With regard to changes in participants' interest to quit smoking no difference could be detected between reducers and non-reducers or active and placebo treatment

\section{Discussion}

This trial confirmed that it is possible to achieve a sustained reduction in cigarette smoking in people unable or not willing to quit. Although the overall success rates were relatively small, active treatment with the nicotine inhaler was more effective in obtaining this reduction than placebo over the entire period of two years. The combination of smoking and using a nicotine inhaler was well tolerated.

Except for the fact that more women were randomised to active (114) than placebo (96) treatment, all baseline parameters in our study group were comparable to the cohorts found in smoking cessation studies. One notable difference, implied by the recruitment criteria, was that our participants were not prepared to stop smoking immediately, although over two thirds said they wanted to stop eventually, whereas all participants are motivated to stop in cessation studies. ${ }^{16}$

As the study of smoking reduction is relatively new, there is no consensus regarding what level of reduction should be chosen to define success. We therefore arbitrarily selected a reduction of $\geqslant 50 \%$ in daily cigarette smoking, verified by a reduction in exhaled carbon monoxide concentrations compared with baseline. Smoking cessation has traditionally been defined as sustained abstinence combined with an expired carbon monoxide concentration of $<10 \mathrm{ppm}$.

\section{Safety}

No serious or important adverse events related to treatment occurred during the study period. Symptoms of possible nicotine overdose were evenly distributed between treatment groups. Throat irritation and coughing were the only symptoms significantly more common in the active treatment group, and this was expected on the basis of previous experience with the nicotine inhaler in smoking cessation studies. ${ }^{12}{ }^{13}$ Our finding, that the combination of reduced smoking and use of the nicotine inhaler was well tolerated, should allay the concern that concomitant use may lead to nicotine intoxication.

\section{Concept of smoking reduction}

One argument against smoking reduction is that encouragement of this strategy may give smokers an easy option and undermine efforts to stop smoking completely, but the converse may also apply. Smoking reduction may promote smoking cessation by allowing smokers to take control of their smoking gradually, and this seemed to be the case in one trial. ${ }^{8}$ Other supportive studies in which nicotine treatments were used to reduce smoking in smokers who were trying to quit suggest that nicotine treatments do suppress smoking behaviour and would thus benefit smokers trying to reduce smoking. For example, in the lung health study $60 \%$ of the participants reduced rather than stopped smoking, and $39 \%$ of these reduced their smoking by at least 50\%. ${ }^{17}$ Similarly, a recent analysis of the 1410 people who smoked both at baseline and at two year follow up in the community intervention trial for smoking cessation (COMMIT), which involved participants in 22 US cities, reported that at two years $17 \%$ had decreased their smoking by $5-25 \%, 15 \%$ by $24-49 \%$, and $8 \%$ by at least $50 \%$. Reduced smoking at two years neither promoted nor undermined cessation at a later date. ${ }^{11}$ In our opinion, the fact that in our

\section{What is already known on this topic}

Smoking cessation has been the sole goal in studies on the treatment of tobacco dependence

Many smokers find it impossible to stop smoking without help because of their dependence on cigarettes

\section{What this study adds}

Smokers who are unwilling or unable to stop smoking abruptly can use nicotine replacement therapy to reduce the amount they smoke

Reduction in smoking was safely achieved with the aid of a nicotine inhaler 
study $10 \%$ (38) of participants unwilling or unable to stop smoking at baseline were abstinent at two years clearly gives support to the idea that smoking reduction can be a step towards abstinence.

Another caveat is that smokers who reduce their number of daily cigarettes may compensate their intake of tobacco toxins by smoking the remaining cigarettes more efficiently. The present study indicates that such compensation may occur to some extent because the reduction in carbon monoxide concentrations was lower than the corresponding reduction in cigarette consumption.

In summary, our study shows that sustained, long term reduction in smoking with the nicotine inhaler can be achieved and maintained. Smoking reduction seems a feasible first step towards improved health and may ultimately lead to complete smoking cessation in people unable or unwilling to stop smoking abruptly.

Contributors: CTB was involved in planning the study, wrote the paper, and was principal investigator for Basle.J-PZ was involved in planning the study and was principal investigator for Lausanne. TD was involved in planning, helped to write the paper, and was responsible for the trial at Pharmacia and Upjohn, Sweden. XvB was involved in planning and was the main study nurse for Basle. AR was the main study nurse for Lausanne. Å carried out the statistical analysis. APP was involved in planning and supervision during the study. US was senior study planner at Pharmacia and Upjohn, Sweden. CTB is guarantor for the study.

Funding: Pharmacia and Upjohn Consumer Healthcare, Sweden.

Competing interests: TD, ÅW, and US are all employed by Pharmacia and Upjohn, Sweden, and AR, CTB, and J-PZ have received funds for research from them.
1 Doll R, Peto R, Wheatley K, Gray R, Sutherland I. Mortality in relation to smoking: 40 years' observation on male British doctors. BMJ 1994;309:901-11.

2 Smoking Cessation Clinical Practice Guideline Panel and Staff. The agency for health care policy and research: smoking cessation clinical practice guideline. JAMA 1996;275:1270-80.

3 Benowitz NL. Pharmacology of nicotine: addiction and therapeutics. Ann Rev Pharmacol Toxicol 1996; 36:597-613.

4 Silagy C, Mant D, Fowler G, Lancaster T. Nicotine replacement therapy for smoking cessation. In: Cochrane Collaboration. Cochrane Library. Issue 3. Oxford: Update Software, 1999.

5 Paoletti P, Fornai E, Maggiorelli F, Puntoni R, Viegi G, Carrozzi L, et al Importance of baseline cotinine plasma values in smoking cessation: results from a double-blind study with nicotine patch. Eur Respir J 1996:9:643-51.

6 Kunze M. Harm reduction: the possible role of nicotine replacement. Prog Respir Res 1997;28:190-8.

7 Jiménez-Ruiz C, Kunze M, Fagerström KO. Nicotine replacement: a new approach to reducing tobacco-related harm. Eur Respir J 1998;11:473-9.

8 Fagerström KO, Tejding R, Westin A, Lunell E. Aiding reduction of smoking with nicotine replacement medications: hope for the recalcitrant smoker? Tobacco Control 1997;6:311-6.

9 DiClemente CC, Prochaska JO, Fairhurst SK, Velicer WF, Velasquez MM, Rossi JS. The process of smoking cessation: an analysis of precontemplation, contemplation, and preparation stages of change. J Consult Clin Psychol 1991;59:295-304.

10 Glasgow R, Klesges R, Klesges L, Vasey M, Gunnarson D. Long-term effects of a controlled smoking program: a two and a half year follow-up. Behav Ther 1985;16:303-7.

11 Hughes JR, Cummings M, Hyland A. Ability of smokers to reduce their smoking and its association with future smoking cessation. Addiction 1999;94:109-14

12 Tønnesen P, Nørregaard J, Mikkelsen K, Jorgensen S, Nilsson F. A double-blind trial of a nicotine inhaler for smoking cessation. JAMA 1993;269:1268-71.

13 Hjalmarson A, Nilsson F, Sjostrom L, Wiklund O. The nicotine inhaler in smoking cessation. Arch Intern Med 1997;157:1721-8.

14 Heatherton TF, Kozlowski LT, Frecker RC, Fagerström KO. The Fagerström test for nicotine dependence: a revision of the Fagerström tolerance questionnaire. Br J Addiction 1991;86:1119-27.

15 Hays RD, Sherbourne CD, Mazel RM. The RAND 36-item health surve 1.0. Health Econ 1993;2:217-77.

16 Bolliger CT. Practical experiences in smoking reduction and cessation. Addiction 2000;95(suppl 1):19-24

17 Murray RP, Bailey WC, Daniels K, Bjornson WM, Kurnow K, Connett JE, et al. Safety of nicotine polacrilex gum used by 3,094 participants in the lung health study. Chest 1996;109:438-45.

(Accepted 4 August 2000)

\title{
Effect of restrictions on smoking at home, at school, and in public places on teenage smoking: cross sectional study
}

\author{
Melanie A Wakefield, Frank J Chaloupka, Nancy J Kaufman, C Tracy Orleans, Dianne C Barker,
} Erin E Ruel

\begin{abstract}
Objective To determine the relation between extent of restrictions on smoking at home, at school, and in public places and smoking uptake and smoking prevalence among school students.

Design Cross sectional survey with merged records of extent of restrictions on smoking in public places.

Setting United States.

Participants 17287 high school students.

Main outcome measures Five point scale of smoking uptake; 30 day smoking prevalence.

Results More restrictive arrangements on smoking at home were associated with a greater likelihood of being in an earlier stage of smoking uptake $(\mathrm{P}<0.05)$ and a lower 30 day prevalence (odds ratio $0.79(95 \%$ confidence interval 0.67 to 0.91$), \mathrm{P}<0.001)$. These findings applied even when parents were smokers. More pervasive restrictions on smoking in public places were associated with a higher probability of
\end{abstract}

being in a earlier stage of smoking uptake $(\mathrm{P}<0.05)$

and lower 30 day prevalence (0.91 (0.83 to 0.99$)$, $\mathrm{P}=0.03)$. School smoking bans were related to a greater likelihood of being in an earlier stage of smoking uptake (0.89 (0.85 to 0.99$), \mathrm{P}<0.05)$ and lower prevalence $(0.86$ ( 0.77 to 0.94$), \mathrm{P}<0.001)$ only when the ban was strongly enforced, as measured by instances when teenagers perceived that most or all students obeyed the rule.

Conclusions These findings suggest that restrictions on smoking at home, more extensive bans on smoking in public places, and enforced bans on smoking at school may reduce teenage smoking.

\section{Introduction}

Restrictions on smoking at work and home are associated in adults with reduced daily smoking rate and increased cessation. ${ }^{1-3}$ As these types of smoking restrictions become more pervasive, ${ }^{145}$ smoking is
Correspondence to:

M A Wakefield melaniew@uic.edu

continued over

BMJ 2000;321:333-7

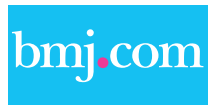

This article is part of the BMJ's randomised controlled trial of open peer review. Documentation relating to the editorial decision making process is available on the $B M J$;s website 